\title{
Body with Body: Interacting with Children with Congenital Deafblindness in the Human Niche
}

\author{
Anstein Gregersen
}

\section{Acknowledgements}

I would especially like to thank Anne V. Nafstad for discussions and comments on the paper. Also thanks to Kåre Letrud and Rosemarie Van Den Breemer.

Kasper Gregersen passed away shortly after this article was written. Anstein Gregersen had the privilege of being his father for nearly four years. Gregersen is also Associate professor of philosophy, and leader of Department of Philosophy at the Inland Norway University of Applied Sciences.

\begin{abstract}
In deafblind studies it is commonly and usefully advised that partners interact close and face-to-face with children with congenital deafblindness. While recognizing face-to-face as an important mode of interaction this paper advances the simple idea that an equally important form of togetherness is body-with-body. Body-with-body interactions are here understood as interactions where two bodies are aligned with each other: the paradigmatic form is where the back of the child is aligned with the stomach and chest of his partner. I argue that this mode of togetherness can enable agency for a child with CDB through making as good as possible the conditions for perception and cognition. The body-with-body mode will make possible perception of the partners body in action; perception of some of the partners emotions; enable joint attention; enable skill acquisition and use of equipment, and finally enhance distal perception.
\end{abstract}

\section{Keywords}

Interactions, interventions, perception, cognition, agency, body, touch. 


\section{Introduction}

This paper is born out of reflections that are both personal and occupational. My daytime is spent as a professional philosopher, sometimes thinking about perception. More personally my wife soon four years ago gave birth to our third child: a few months down the road of medical investigations it was clear that Kasper had congenital deafblindness (from now on "CDB"). He had no residual sight or hearing, he was completely blind and deaf. By the end of his first year Kasper had bilateral Cochlear Implants (CI). After the functional diagnosis, Statped, Norways national service for special needs education, started to follow up on Kasper and they advised us from the beginning to be physically close to him. In deafblind studies interactions between the child and his environment are seen as crucial for the development of the child. This might in some ways seem obvious. However, due to the either reduced or absent function of sight and hearing the connection between a child with CDB and the environment takes on different shapes than it does for seeing and hearing children. One such difference is that the normal physical distance that seeing and hearing people engage at is not useful for interactions with children with CDB. In deafblind studies this basic fact has led to the advice that partners and children with CDB engage in close face-to-face interactions.

Yet, while recognizing face-to-face as an important mode of interaction I think there is an additional and beneficial way of encountering the world that can be called "body-with-body". Body-with-body interactions are here understood as interactions, or a form of togetherness, where two bodies are close and aligned with each other. The paradigmatic form of alignment is perhaps the one we used on Kasper for nearly four years. He spent a considerable amount of time in the baby carrier in a position such that his back was aligned with the stomach and chest of his partner. This is not the only possible form of alignment; modes of togetherness can be thought of on a range from straightforward face-to-face to body-with-body interactions. Often practitioners will use different forms for different purposes without any need for further theorizing. But, for the sake of simplicity I will here discuss the paradigmatic case. Hopefully through the discussion it will be clear enough how and when others forms might be beneficial. Furthermore, since my primary example is a small boy I will talk about children with CDB. Though I do think that the more general points are applicable to persons with CDB at later stages in life as well.

In Part I I discuss why, in at least parts off, deafblind studies interactions are recommended to be in face-to-face mode. The considerations behind Nafstad and Rødbroe's influential Communicative Relations model (2015) points towards face-to-face interactions as the right mode of closeness for balancing the child's dependency on the environment with the development of independence and agency.

In Part II I turn to some topics from the philosophy of perception that are relevant to the perceptual conditions that CDB entails. I argue that a child with CDB often will experience 
their perceptual field as unstable, and then not conducive to perception and cognition. This raises the question of what it takes to stabilize the perceptual field enough so that the child can adequately perceive the environment? I should note right away that "adequacy" is not premised on the standards of seeing people, but understood in relation to the possibilities of sense-making for a child with CDB. I argue that stabilizing the perceptual field demands that the child has an active bodily access to his partners.

Based on these considerations Part III investigates how the partner through the bodywith-body mode can immerse the child into significant parts of the human niche. By making the environment perceptible the body-with-body mode can then aid agency on part of the child with CDB. My suggestion, then, is that contrary to first impressions the body-with-body mode is not a dependent making form of closeness, but rather enables agency and so independence.

\section{Part I The Need for Intervention}

Body-with-body interactions, as face-to-face interactions, are interventions into the environment of the child with CDB. In order to discuss the benefits of the various forms of interventions it will be helpful to have a common theoretical framework. Some of the strongest reasons for face-to-face interactions are found implicitly in the work of Nafstad and Rødbroe. Their model is inspired by Uri Bronfenbrenner's bioecological approach to human development. While Bronfenbrenner revised his model of human development several times in collaboration with other psychologists, I will here only briefly explain some main elements of the mature version (Bronfenbrenner \& Evans, 2000) as a stage setting.

The bioecological model is focused on environmental systems and processes in order to understand the development of an individual. The model emphasizes "'the dynamic interplay of processes across time frames, levels of analysis, and contexts', in which 'time and timing are central" (Bronfenbrenner \& Evans, 2000 p.116). Central to Bronfenbrenner's theory is the Process-Person-Context-Time Model (PPCT):

A developmental outcome at a later point in time $\left[\mathbf{D}_{2}\right]$ is a joint function of a process; characteristics of the developing person; the nature of the immediate, 'faceto-face' environmental context in which the person lives; and of the length and frequency of the time interval $\left[\mathbf{T}_{2}-\mathbf{T}_{1}\right]$ during which the developing person has been exposed to the particular process and to the environmental setting under consideration (Bronfenbrenner \& Evans, 200 p. 119, emphasis in the original). 
The idea, then, is that a person with a set of characteristics interact with his immediate environment. This interaction leads to development if the person has been exposed frequently and long enough to it. This enduring interaction is called a "proximal process":

A proximal process involves a transfer of energy between the developing human being and the persons, objects, and symbols in the immediate environment. The transfer may be in either direction or both; that is, from the developing person to features of the environment, from features of the environment to the developing person, or in both directions, separately or simultaneously. (Bronfenbrenner \& Evans, 200 p. 118, emphasis in the original).

Bronfenbrenner and Evans uses developmental outcome as the criteria for distinguishing between proximal processes: A good outcome is if a proximal process creates competence; a bad outcome is if it leads to dysfunction.

When discussing closeness it is important to realize that the question is a normative one: how should we intervene in the environment of the child with CDB in order to create competence? Due, at least partially, to the conditions for perception that CDB entails this normative dimension becomes more accentuated with children with CDB compared to seeing and hearing children.

Sight and hearing are often characterized as the distal senses. By sight we see can see a sailboat far ashore, or the apple tree in a garden a few houses down. We can hear a helicopter high above, or a dog barking from the neighbour house. Other senses can also grasp aspects of the world at a distance. Sea air, or mountain marshes in summer time, not to forget soil fertilized with cow manure, gives off smells that we can discern on longer distances. A train passing at high speed will give of air pressure that our tactile sense can perceive. But in many ways seeing and hearing are the most efficient and detail rich senses when it comes to perception at long distances for humans.

Social interaction also happens mostly at distance (I leave the obvious counterexamples to the reader's imagination), though closer than in the examples above. Our ecological niche is "shaped and sculpted by the rich variety of social practices that humans engage in" (Rietveld \& Kiverstein (2014)). And these practices are chiefly based on bodies that have functional sight and hearing. Consider, for instance, the way we interact in elevators: we are all expected to face the elevator door, and get uncomfortable if someone breaks the norm. This norm is not by itself very functional outside the bounds of sight.

With this point about the challenges CDB entails for distal perception we can see how Bronfenbrenner's model is fitting for an overall approach to understanding how dysfunction and competence can result from proximal processes that children with CDB are engaged in. Social cognition is, as said, particularly challenging. The child with CDB is likely to express 
cognition through bodily gestures. These gestures will be unconventional and deviate from that of the larger culture where conventions are based on bodies with functioning sight and hearing. It is, also, difficult for partners to abandon these conventions in order to understand the bodily gestures and, more generally, the point of view of children with CDB. If this attempted communication process has been frustrating enough for the child he might even stop trying to communicate. In other words, CDB will often lead to low readability on both sides of the interactions: It is difficult for partners to read a child with CDB; and it is difficult for a child with CDB to read partners. It is clear that these kinds of proximal processes might easily lead to dysfunction. As Nafstad points out, this difficulty with social cognition will also make it easier for professionals assessing cognitive activity by a child with CDB to notice deviance from "culturally expected forms" (2014, p.60), than it is for them to recognize the actual use of cognition. If, however, the child with CDB's gestures are understood by the environment and met with appropriate feedback communicative competence is built up.

Returning to the explicit normative question, how can the environment be optimized for the child with CDB? Naftstad and Rødbroe's Communicative Relations model (Nafstad \& Rødbroe, 2015) addresses this issue. While the PPCT model pictures human development from a high altitude Nafstad and Rødbroe's model is geared towards establishing communicative relations partly by way of dialogicality and embodiment theory. For Nafstad and Rødbroe transfer of energy between the person with CDB and their environment can move towards competence if the partner is socially available and the person with CDB has trust in the their partners (Nafstad \& Rødbroe 2015, p. 90). This availability and trust makes possible both social interactive play, affectionate interactive play as well as explorations from base. This again can lead to spontaneous embodied referential gestures by the child with CDB. Which, if the interactions are optimized, can lead to conversational symbolic interactivity.

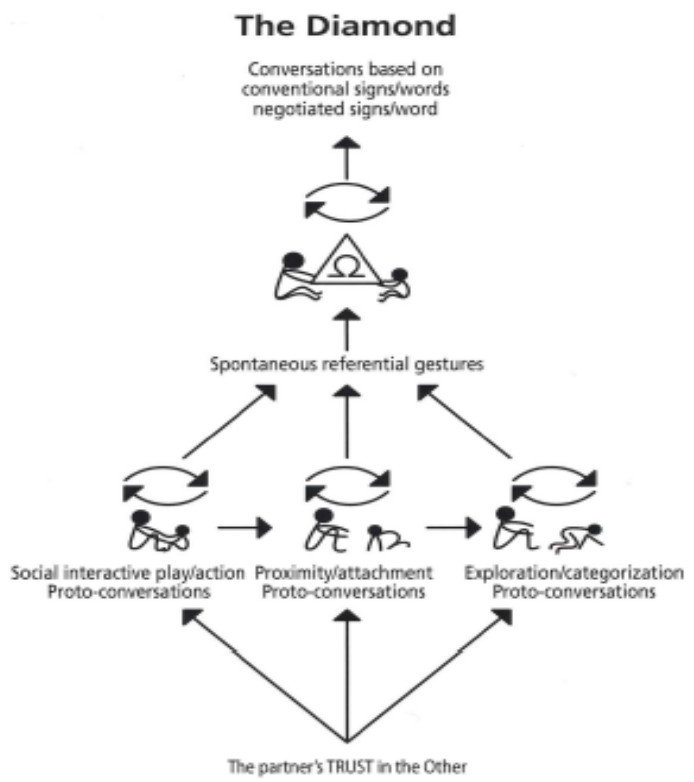

Figure 1. The Diamond 
As in Bronfenbrenner and Evans' model, Nafstad and Rødbroes emphasizes closeness in the form of face-to-face interaction. The term "face-to-face", however, is not meant to be taken at face value. It is recognized that a face-to-face interaction can manifest itself in different forms where faces are actually not facing each other:

Face-to-face relations can have unusual outer forms, but still fulfil the same basic relational function. This means that the fundamental reciprocity dimension in the a face-to-face relation can, for example, be played out back-to-back, foot-to-foot or hand-to-hand. The important issue is that the relation is characterized by both parties being oriented towards one another no matter the appearance of the outer form. (Nafstad \& Rødbroe, 2015, p. 53.)

It is clear that Nafstad and Rødbroe intends something quite wide with "reciprocity". Reciprocity can manifest itself in different manners, and interactions with people with CDB gives vivid examples to this. Notice, however, that the form of reciprocity in the interactions mentioned (face-to-face, feet-to-feet etc.), and the illustrations in the diamond, are quite straightforward conversation-like. Reciprocity is, implicitly, understood as a conversation where meanings are exchanged. This is an intentional and well-justified move by Nafstad and Rødbroe: ${ }^{1}$ Given the low readability there is a real danger that the child with CDB will not be seen or heard in the proper manner. In order to secure that the voices of children with CDB are taken seriously as independent contributions Nafstad and Rødbroe picture the desired interaction as a meeting between two people, each with their own voice.

Taking this point further we can see as a potential worry that the body-with-body mode that I recommend might lead to an unhealthy relationship: the child with CDB passively gets moved around in the world and depend on the partner both for perception and action. My argument will be that this worry can be lessened if we see what perception demands. This takes us back to the issue of trust. While trust in partners is necessary, trust must also be understood explicitly in relation to perception. Agency in tactile perception requires that the perceiver conceives of the environment as trustworthy for exploration. One obvious part of this is that the environment cannot be conceived as physically threatening. Another part is that the perceiver must trust the environment to be conducive for perception and cognition.

In the following part I will discuss first one challenging aspect of how a person with CDB's perceptual field relates to the environment. My claim here is that CDB entails in the real world a perceptual field that partly will be experienced as unstable, or not trustworthy for perception and cognition. Secondly, I will argue that tactile, and visual, perception demands agency, and if the conditions for agency are met it is possible to stabilize the perceptual field.

\footnotetext{
${ }^{1}$ Anne V. Nafstad in personal conversations brought my attention to this issue, and much of it would have escaped me without her remarks.
} 
In the third part I will argue that the body-with-body mode is helpful in making the perceptual field more stable and conducive to perception and cognition. So, then a longer period in a body-with-body mode should not create passivity and problematic dependency, but make agency possible.

It should now be clear that my discussion of body-with-body interactions is not targeted towards developing a whole new approach with a deep abyss between face-to-face and bodywith-body interactions, rather the point is to further elaborate modes of desired interactions. Shortly put, although Nafstad and Rødbroe give the PPCT model more detail in relation to persons with CDB I think the forms of interactions in the proximal processes are too restrictive. I want to put somewhat more weight on the conditions for perception and cognition in these processes.

\section{Part II Stability in the Perceptual Field}

Let us return to Bronfenbrenner's very schematic PPCT model. This model understands human development as the result of the joint function of: the characteristics of the individual; how the immediate environment is; how often and how long the individual has been exposed to a particular process and environmental setting. As the short discussion of distal perception and social cognition showed the reduced or absent function of sight and hearing from birth on influences the characteristics of the child, and how he can relate to the environment. A competence building intervention must take into account the perceptual relation between the child with $\mathrm{CDB}$ and his environment. There are many things to say about this relation, but here I want to discuss one aspect that seems central.

The philosopher Immanuel Kant conducted a thought experiment that connects with the perceptual relation between a person with $\mathrm{CDB}$ and his environment. In The Critique of Pure Reason (1781/1787) Kant had argued that nature necessarily is organized by (transcendental) laws as a system. These laws in some way exists before experience/perception. However, a few years later in the Critique of Judgment (1790) Kant asks the reader to imagine that this does not mean that nature at the level of (empirical) experience is such that we can experience it as a system. We can imagine that nature manifests itself to us as a "crude chaotic aggregate" (Kant, 1987, p. 209). If the environment manifests itself to us as a crude chaotic aggregate it is impossible for us to find kinship between the different perceptions: we will not be able to form real experiences of things, or find commonality between the messy perceptions to subsume them under concepts.

Does Kant's thought experiment capture how perception actually work in the environment, or is this just a philosopher's fabrication? It would seem the latter if we consider 
Merleau-Ponty's following description of visual and tactile perception. Philosophers tend to focus solely on visual perception, so Merleau-Ponty takes those who are concerned with CDB in a helpful direction by including tactile perception. He sees sight and touch ("the sensing being" below) as relating in quite similar manner to the object ("the sensible" below):

The sensing being [le sentant] and the sensible are not opposite each other like two external terms, and sensation does not consist of the sensible invading the sensing being. My gaze subtends the color, the movement of my hand subtends the form of the object, or rather my gaze pairs off with the color and my hand with the hard and the soft. (Merleau-Ponty, 2012, pp. 258-259).

Merleau-Ponty's description of actual perception is quite different from Kant's thought experiment. For Merleau-Ponty the relation between the seeing and touching perceiver and the environment is: "not opposite"; "not the sensible invading". Rather: "gaze subtends"; "hand subtends"; "gaze and hand pairs off with". Notice that Merleau-Ponty's description here is of perception of a stable and predictable environment accessible to the perceiver in a stable and predictable manner. At the ground-level there is a harmony between the perceiver's perceptual capacities and the environment that lets them interact in the manner of subtending and pairing off. The environment here is amendable to our perceptual capacities, and the environment does not "invade" the perceiver. For our perceptual and cognitive capacities the environment is trustworthy. To put it abruptly, what Merleau-Ponty offers here is a majority description of perception; the majority that can use sight. Here is why.

In Merleau-Ponty's description the object of tactile perception is stable for the perceiver in time and space. Let us consider a simple situation of perception by a child with CDB where the stable object is in a more full context than in Merleau-Ponty's description:

One time I was playing with Kasper and an iPad, he was sitting in a working chair, faceto-face with me. Both of us were engaged with a music app when the iPad suddenly ran out of power, and the music stopped. I turned sideways and picked up a cord from a bag. I plugged the cord into the wall socket, and then into the iPad. Suddenly the music returned. Magic!

Most people working with children with CDB will find this kind of examples familiar. The sequence of events in the example would be easy to understand for seeing and hearing children. Their capacities for distal perception will give them a comprehensible visual field. For Kasper, however, only some of the perceptual information in this situation could be made sense off. While exploring the iPad the particular interactions in the hand-to-hand mode might have made sense. The object at least was accessible for him. But from the moment the 
battery ran out, little of it can. He must have felt my hands moving away, possibly that I was bending over since my belly touched his feet. He will have heard some sounds with the CI, perhaps felt the cord being plugged into the iPad, and so on. But these perceptions must have seemed haphazard to him. He must partly have experienced what Kant in one place called a "rhapsody of perceptions" (1997, p. A156/B195), and as quoted before "A crude and chaotic aggregate without the slightest trace of a system" (Kant, 1987, p. 209.) in another. Out of this aggregate no adequate perception and cognition can arise.

People with CDB will be able to make sense of many things in their perceptual field, but often there will be events in the field that come into it in such a manner that it is not possible to perceive the context and make sense of the happenings. Their perceptual field becomes unstable through no fault of their own; parts of the environment does "invade" it.

Here is another simple example showing this. An object shortly bumped into the foot of Kasper. What happened? What was the object? A sighted person would have seen that it was a shoe; someone unintentionally kicked him while passing by. Kasper, due to the restricted distal perception, did not have the possibility of forming the short bump to his legs into a complete experience. For a sighted person it might be possible to say that the gaze pairs off with the shoe and the person wearing it, thus making the environment stable. For Kasper the time and manner of movement the shoe was in his perceptual field made it impossible to form an experience.

Shaun Gallagher describes people with CDB's experiences and existence the following way:

This relates to the fact that blindness is not experienced by the congenitally blind person as missing sight; nor is congenital deafness experienced as the missing of some positive sense - with all other aspects of existence remaining equal. As MerleauPonty indicated, such congenital conditions determine a "complete form of existence" $(2012$, 107). Being deafblind is not equivalent to having an incomplete form of experience; it is rather a different form of experience that holds together in a holistic fashion. (Gallagher, 2017, p. 55)

Kudos to Gallagher for understanding that CDB should not be understood as an incomplete form of experience ("blindness as blackness"), but what he misses here is that the conditions for having experiences holding together in a holistic fashion often are, exactly, missing. The problem is that events in the environment are both not always fully accessible for the person with CDB's perceptual capacities, and still impinges on their perceptual field. The challenges with both distal perception and social cognition accounts for this; the world is not always amendable to perception for a child with CDB. It might be impossible to completely remedy this instability in everyday life, but clearly interactions should have that as one goal. 
And it is probably the case that it is in everyday social life that a child with CDB will experience a confusing perceptual field most troublesome. These are also the kinds of situations where interventions are possible. The challenge is to find ways of interacting where the person with CDB will have the opportunity to comprehend his various sense experiences.

\section{Perception and Agency}

How should interactions be designed so that the child with CDB can perceive and cognize as adequately as possible? In philosophy there is a large debate about the role of action in visual perception. Philosophers have tended to think that visual perception should be understood as a state where seeing humans gets determinate content delivered. This understanding is not easily transferred to tactile perception; a child with CDB will explore mundane objects as iPads and carrots actively over time. In a theory of tactile perception enduring action must have a prominent role given the small surface, for instance, each finger can perceive at any given moment: often small instances of perception will be built into a larger structure in the process of sense-making. The point here is quite simple, tactile perception by a child with CDB is dependent on the person's own agency.

So far I have argued that Kant's thought experiments gives us a better understanding of children with CDB's perceptual relation to the environment than Merlau-Ponty's phenomenological majority description. But both Kant and Merleau-Ponty ${ }^{2}$ argues that perception and cognition is dependent on interactions with the environment. Merleau-Ponty describes this interaction as a kind of dialog ${ }^{3}$ between the body and the environment:

A sensible that is about to be sensed poses to my body a sort of confused problem. I must find the attitude that will provide it with the means to become determinate ... I must find the response to a poorly formulated question. And yet I only do this in response to its solicitation... . The sensible gives back to me what I had lent to it, but I received it from the sensible in the first place. (Merleau-Ponty, 2012, p. 259)

Merleau-Ponty's description here is meant to cover both vision and touch. In both cases the body engages in finding an attitude, an activity, that will take the perceiver from being engaged with an unknown sensible to determine what the sensible is (what kind of object is the sensible? what kind of activity? Etc.). What Merleau-Ponty brings to the table, more explicitly than Kant, is the whole body in relation to determining the sensible.

This is important for two reasons. First, it corresponds to the way children with CDB uses their whole body actively, finds attitudes, in tactile perception. If, that is, the environment is experienced as conducive to tactile perception, and so cognition. Secondly, it shows that the

\footnotetext{
${ }^{2}$ See Matherne, 2016, for a discussion of similarities between Kant and Merleau-Ponty on schematization.

${ }^{3}$ See e.g. Ted Toadvine 2016 for further discussion.
} 
partners to the children with CDB also uses their whole body in visual perception through adjustments and attunements. This, I will argue, is an important point.

\section{Part III Body with Body}

We have seen that the perceptual field of a child with CDB can partly be experienced as a rhapsody of perceptions. To remedy this situation as far as possible we have also seen that it must be possible for the child with CDB to engage in active explorations of the environment. Importantly partners also use their whole body when they perceive and interact in the environment; intentionality should be understood as a whole body state. These considerations sets the stage for my argument for utilizing the body-with-body mode in many interactions. In the following I look at different aspects of interactions, and what they are aimed at. In A) to D) the structure is that there is a risk of a rhapsody of perceptions in the interactions, but the body-with-body mode can significantly reduce this. In E) the concern is more with optimizing perception.

\section{A) Perceiving the partners body and partaking in activities}

Due to the challenges with distal perception and social cognition children with CDB often find themselves in the peculiar position of having to rely heavily on close interactions with partners to access the environment. Some of these interactions, as in the iPad example above, are directly between the child with $\mathrm{CDB}$ and the partner. In other interactions the partner functions as an intermediary between the child and the environment, as for instance in group play. What is striking is that the partner's body must be accessed through touch, and this has ramifications for how the interaction should go.

First of all, the partners body must be related adequately to the environment. For instance in a football game the partner's body must be adjusted correctly to the game. Secondly, the partner's body must be accessible in the right manner; it must be possible to access the whole body of the partner while the partner is engaged in football. The clear risk is that without this relation only fragments of the process and environmental setting will be perceptible for the child with CDB, the rest will seem like a rhapsody. This consideration alone points towards the benefit, and at times necessity, of adopting a togetherness in form of body-with-body. The alignment of bodies will increase the tactile access the persons have to each other, thereby making them more perceptually attuned to each other. This increase in tactile access will be both in surface covered, back against stomach and chest, legs feeling the other's leg moves, arms being coordinated. The increase will also be in how the bodies are used. It will give an understanding of the partners body in action, in a different manner from that off the face-to- 
face interaction. The body-with-body mode enables a patterned embodied perception of the partners body in action. Just to be clear, this body-with-body alignment can also incorporate a hand-with-hand alignment that, as we will see below, in many situations will be crucially important.

Returning to the iPad episode above we can see that the way this played itself out, Kasper must have experienced partly a "rhapsody of perceptions". If however his whole body had been aligned with my body, in the body-with-body mode, he would have access to my acting body in a quite different manner. Of course, he would not have seen what I saw, but his perceptual field would be much better adjusted to what happened around him.

I want to note one more practical aspect here. In many everyday situations a child with CDB will have partners around him. Often for simply mundane reasons, like coordinating their activities with the child with $\mathrm{CDB}$, the partners will direct their attention towards each other. These situations will be perceptually challenging to the child who cannot make sense of the whole circumstance, and at the same time certainly some of it will be within reach of their perceptual capacities. Aligning the child's body with a primary partner will go some way towards making aspects of the situation more adequately perceptible.

\section{B) Perceiving emotions}

Another related factor is that of perceiving emotions in partners and groups. Social cognition is as said difficult for a child with CDB. But some mental states can manifest themselves in the whole body and be accessed more directly by a tactile perception of the large parts of the body. Kasper has bilateral CI, but we have observed that often he was uncertain how to relate to laughter in the room while sitting in his working chair. However, in a body-with-body mode he attuned himself to his partners expressions, like laughter, quite quickly.

\section{C) Joint attention and body-with-body}

If the access to the partners body is such that the person with CDB can make sense of what the partner is doing they can establish joint attention:

Kasper and his partner has just walked into the hallway of the kindergarden. Kasper, as usual, hangs forward facing in the harness. His body aligned to his partner's. After having taken the partner's outercoat off, and together inspected the zipper, the partner turns to her, right facing a wall at short distance. Kasper leans forward in the harness touching the wall with his nose. The partner also leans in, and touches the wall with her nose. This is a short episode, but the partner reported afterwards that she felt Kasper giving her a message with the body that she should move out from the wall. As they turn left Kasper gives the signs of "done", "nose", or 
perhaps "smelling", "together" after eachvother. Clearly joint attention has been established, and Kasper has been in a position where he can be the agent in initiating the joint attention. ${ }^{4}$

A key insight of the phenomenological tradition is that we perceive as embodied beings. This means that we encounter objects in the world from a particular perspective. My laptop, for instance, is encountered from a particular point of view. I see the keyboard and the screen, but not the top of the lid or the bottom of the laptop. But in what way is the lid and the bottom absent for me? Are they absent in the same manner the laptop in the next office down the hallway is? Merleau-Ponty's concept of "motor intentionality" captures that the top of the lid and the bottom of the laptop is not encountered as simply not being there. The lid and bottom is present as possibilities: the lid and bottom is present as what I would be seeing if I had positioned myself differently. The motor possibilities of the body shapes the perceptual content.

For persons with functioning sight it is possible to understand other people's perspective by looking at them and seeing how they will see. Now, if Merleau-Ponty is correct, joint attention demands access to the other's embodied perspective. A hand-to-hand interaction without the body-with-body alignment can do some of this work if we are talking about small to middle-sized objects, often outside a particular context of usage. But in order to share the perspective in environmental perception bodily alignment seems close to necessary in order to enable a useful hand-with-hand alignment. Notice that this goes both ways. A partner also need the bodily alignment to understand the bodily perspective of the person with CDB.

\section{D) Skills}

Kasper is in the kitchen of his kindergarden helping to prepare the daily warm lunch, today its fishsticks with potatoes and carrots. Kasper is working out a problem that might not occur to most people with functioning sight. Namely, how is a carrot peeled? But Kasper is not facing this problem sitting in his wheelchair. Kasper and his partner are facing the task together, and they are facing it from the same point of view, or perspective. By hanging in a baby carrier Kasper's body is aligned with his partners body. In their sharing the point of view in this bodily, basically tactile, manner Kasper has access to the way his partner moves and adjusts her body while she peels carrots. His perception is grounded in a perception of his partners actions.

Kasper first thoroughly explores the carrot, measures its length and feels its surface by both hands and cheeks. He then moves his hand to the peeler, quickly experiencing that it's a sharp tool. The partner then starts peeling the carrot with a peeler. Kasper puts his hands over the assistant and feels her movements. Kasper shows clearly that he has understood how carrots are peeled, after a few repetitions Kasper imitates the movement of the peeler with his right hand over his left that represents the carrot. He also stretches his right hand out, trying to reach a boy sitting next to him and moves his own hands over the carrot using a "together" sign. At the same

\footnotetext{
${ }^{4}$ Thanks to Hege Høgmo and Gøran Forsgren for video and videoanalyzes.
} 
time orally saying "hi" several times. Basically telling the boy that they should together investigate the carrot. ${ }^{5}$

This episode from Kasper's life nicely exemplifies one aspect of Tim Ingolds ecological conception of skill acquisition:

...I do not deny that the learning of skills involves both observation and imitation. But the former is no more a matter of forming internal, mental representations of observed behaviour than is the latter a matter of converting these representations into manifest practice. For the novice's observation of accomplished practitioners is not detached from, but grounded in, his own active, perceptual engagement with his surroundings. And the key to imitation lies in the intimate coordination of the movement of the novice's attention to others with his own bodily movement in the world. Through repeated practical trials, and guided by his observations, he gradually gets the 'feel' of things for himself - that is, he learns to fine-tune his own movements so as to achieve the rhythmic fluency of the accomplished practitioner... And in this process, each generation contributes to the next not by handing on a corpus of representations, or information in the strict sense, but rather by introducing novices into contexts which afford selected opportunities for perception and action, and by providing the scaffolding that enables them to make use of these affordances. This is what James Gibson (1979:254) called an 'education of attention'. Ingold, 2011, pp. 353-354)

What is crucial for my argument here is that Ingold points out that in learning skills the novice has an active perceptual engagement with the environment, and primarily through an intimate coordination of his attention to the masters bodily movements with the novices own bodily movements. Ingolds description is based on the function of vision. For a novice with sight this education of attention can happen at distance. He can repeatedly see how the master is doing it, and then gradually achieve the rhythmic fluency. How will this learning of skills play out for a novice with CDB? It will be necessary with prolonged tactile access to the body of the partner in order to educate the attention. In the example with carrot peeling Kasper had his attention to his partners movements, and started to imitate her movements. If we focus only on the movements, i.e. Kasper and his partner's bodies in isolation, in the skill of carrot peeling we see that it's a question of a whole body in action. Even for such a hand based skill as carrot peeling Kasper benefited from access to the arms of his partner, her bodily adjustments, the rhythmic coordination of both arms. In short, it seems necessary with a body-with-body mode for educating the attention of the novice with CDB simply in the movements.

\footnotetext{
5 Thanks to Hege Høgmo and Gøran Forsgren for video and videoanalyzes.
} 
Consider the skill in the larger context. As mentioned Ingolds has an ecological conception of skills. Skill is not an "attribute of the individual body in isolation but of the whole system of relations constituted by the presence of the artisan in his or her environment" (Ingold, 2011, p. 291.) Given this bodily presence of the artisan in the environment it also seems that the introduction to the whole ecosystem of the skill demands the body-with-body mode. I take it that Kasper asking the boy sitting next to him is an expression of him understanding that the skill takes place in an larger context and that the skill matters. Being body-with-body with his partner he gets introduced to the skills place in the human niche.

\section{D) Using equipment}

Many of the entities we encounter in the world are encountered as equipment. The philosopher Martin Heidegger went as far as to claim that it is in use that the hammer uncovers the specific character of the hammer. The hammer is then not manifest through detached observation of it. It is stretching it somewhat too far to claim that a person with CDB and his partner encountering equipment in a face-to-face interaction is just a detached spectator perspective. But in practical life this will often be the case. For instance investigating a carrot peeler outside of the practical context certainly is too detached from the use of the peeler to show to the person with CDB what a carrot peeler is. It will be most helpful with the full practical context of the carrot peeler and this demands a bodily alignment between the child with $\mathrm{CDB}$ and his partner.

\section{F) Enhancing distal perception}

When the person with CDB can make sense of the partners body in action, then by being aligned to the partners body the perceptual system of the person with CDB can also be enhanced. The person with CDB can be coupled into a perceptual system that is different, and has more capacity for distal perception. One aspect is simply in terms of reach, the child with CDB will align herself with a person with a bigger operation radius. And the partner will have functioning distal senses that will increase understanding and operation that the child can latch on to. This will be particularly important for small children and those children that cannot move on their own. This enhanced capacity for perception will hopefully again give the person with CDB more agency down the road.

This method of enhancing perception through the use of equipment or other living beings is the staple practice of the blind community. Just think of white canes and guide dogs. Rod Michalko, a sociologist working in disabilities studies and guide dog user, gives an interesting description of how his sense of distance changed when he first used a guide dog: "I experienced an expansion of my immediate environment...Leo seemed to bring my physical environment closer" (Rod Michalko, 1999, p.26). Put rhetorically, why should not a human being, properly trained, be as good an perception enhancer as Leo, the dog? 
It is no coincidence that Michalko and Leo were not in a face-to-face mode, they shared a basic perspective in how their bodies were coordinated. An enhancement of perception cannot be equally well realized in a face-to-face mode.

\section{Concluding Remarks}

To develop agency a thinking being should experience the environment as amendable to his capacity for thought. So, conditions for perception and cognition must play a pivotal role in designing interactions for children with CDB. Understanding the human niche often demands understanding how bodies attune to other bodies and non-living objects. Giving the child with CDB the best conditions for understanding the human niche will then often demand an bodily alignment between the partner and child. To attune intellectually to each other the child and the partner must also attune bodily. And with the bodily and intellectual attunement comes the possibility for the child to develop adequate agency in the human niche.

\section{References}

Bronfenbrenner, U. \& Evans, G. W. (2000), Developmental Science in the $21^{\text {st }}$ Century: Emerging Questions, Theoretical Models, Research Designs and Empirical Findings. Social Development, 9: 115-125. doi:10.1111/1467-9507.00114

Gallagher, S. (2017). Embodied Intersubjective Understanding and Communications in Congenital Deafblindness. Journal of Deafblind Studies on Communication, 3(1), 46-58.

Ingold, T. (2011) The Perception of the Environment. Essays on Livelihood, Dwelling and Skill. New York: Routledge University Press.

Kant, I. (1997). Critique of Pure Reason. Trans. Paul Guyer and Allen Wood. The

Cambridge Edition of the Works of Immanuel Kant. New York: Cambridge University Press.

Kant, I. (1987). Critique of Judgment. Trans. By Werner S. Pluhar. Indianapolis: Hackett Publishing Company.

Matherne, S. (2016). Kantian Themes in Merleau-Ponty's Theory of Perception. Archiv für Geschichte der Philosophie, 98(2): 193-230.

Merleau-Ponty, M. (2012). Phenomenology of Perception. Trans. D.A. Landes. New York: Routldge.

Michalko, R. (1999). The Two in One. Pennsylvania: Temple University Press.

Nafstad, A.V. (2014). Optimizing Interaction: A Precondition for Assesing Cognition" in Ask Larsen, F. \& Damen, S. (ED.) Guidelines for Assessment of Cognition in Relation to Congenital Deafblindness. Stockholm: Nordic Center for Welfare and Social Issues. 
Nafstad, A.V. \& Rødbroe, I.B. (2015). Communicative Relations. Interventions that create communication with persons with congenital deafblindness. Statped Sørøst, Fagavdeling døvblindhet/kombinert syns- og hørselsvansker. Aalborg, Materialcenteret.

Rietveld, E. \& Kiverstein, J. (2014). A Rich Landscape of Affordances. Ecological Psychology, 26(4), 325-352.

Toadvine, T. (2016). Maurice Merleau-Ponty. The Stanford Encyclopedia of Philosphy (Winter 2016 Edition). Retrieved from https://plato.stanford.edu/archives/win2016/ entries/merleau-ponty/.

Anstein Gregersen, Associate Professor of Philosophy, Head of Department of Philosophy, Inland Norway University of Applied Sciences, Postboks 400, 2418 Elverum, Norway; e-mail: <anstein.gregersen@inn.no>. 